\title{
ORGANIZAÇÃO POLÍTICO-PEDAGÓGICA E CURRICULAR NA FORMAÇÃO DE PROFESSORES DO CAMPO EM CIÊNCIAS DA NATUREZA NO BRASIL ${ }^{1}$
}

\author{
POLITICAL-PEDAGOGICAL AND CURRICULAR ORGANIZATION \\ IN THE TRAINING OF FIELD TEACHERS IN NATURE SCIENCES IN \\ BRAZIL
}

\section{ORGANIZACIÓN POLÍTICO-PEDAGÓGICA Y CURRICULAR EN LA FORMACIÓN DE PROFESORES DE CAMPO EN CIENCIAS DE LA NATURALEZA EN BRASIL}

\author{
Geize Kelle Ribeiro ${ }^{2}$ \\ Pesquisadora do Grupo de Pesquisa e Extensão em Ensino de \\ Ciências e Formação de Professores - GEPEEC - UFCAT/CNPq. Catalão- GO. \\ E-mail: geize.ribeiro1@gmail.com \\ ORCID: https://orcid.org/0000-0003-4053-7788
}

Wender Faleiro ${ }^{3}$

Professor da Unidade Acadêmica Especial de Educação e do Programa de Pós-Graduação em Educação - Universidade Federal de Goiás, transição para Universidade Federal de Catalão.

Líder - Fundador do Grupo de Pesquisa e Extensão em Ensino de Ciências e Formação de Professores GEPEEC - UFCAT/CNPq. Catalão- GO.

E-mail: wender.faleiro@gmail.com ORCID: https://orcid.org/0000-0001-6419-296X

\footnotetext{
Resumo: A Licenciatura em Educação do Campo é um curso em consolidação daí surge a necessidade de se discutir a formação de professores da Educação do Campo no âmbito acadêmico de nosso país, tendo como foco suas contribuições para o desenvolvimento rural e para a sociedade nacional, bem como para a superação de processos de exclusão sociohistóricos para educação desses sujeitos. Como as LEdoCs com habilitação em Ciências da Natureza organizam o trabalho político-pedagógico e curricular por área na formação inicial de professores? Para responder à pergunta utilizamos as técnicas da análise documental dos Projetos Político-Pedagógicos dos cursos de Licenciatura em Educação do Campo com

1 Alguns trechos desse artigo estão contidos no e-book "Organização político-pedagógica na formação de professores do Campo em Ciências da Natureza no Brasil” (RIBEIRO; FALEIRO; ALMEIDA, 2020).

2 Mestranda em Educação pela Universidade Federal de Goiás.

3 Pós Doutor em Educação pela Pontifícia Universidade Católica de Goiás.
} 
habilitação em Ciências da Natureza no Brasil. Nossa intenção com essas análises não é propor uma maneira certa ou errada de se formar professores do Campo nem tecer comparações entre os PPPs dos cursos analisados, mas compreender como esses processos formativos, mesmo que parcialmente, contribuem para o fortalecimento da Educação do Campo.

Palavras chave: Formação de professores. Formação por área. Matriz Curricular.

\begin{abstract}
The Licenciatura em Educação do Campo is a course under consolidation, hence the need arises to discuss the training of rural education teachers in the academic scope of our country, focusing on their contributions to rural development and to national society, as well as to overcoming socio-historical exclusion processes for the education of these subjects. How do LEdoCs with qualifications in Natural Sciences organize political-pedagogical and curricular work by area in initial teacher training? To answer the question we used the techniques of documentary analysis of the Political-Pedagogical Projects of the Degree courses in Rural Education with qualification in Natural Sciences in Brazil. Our intention with these analyzes is not to propose a right or wrong way to train teachers in the field or to make comparisons between the PPPs of the courses analyzed, but to understand how these training processes, even if partially, contribute to the strengthening of rural education.
\end{abstract}

Keywords: Teacher training. Training by area. Curriculum.

Resumen: La Licenciatura em Educação do Campo es un curso en proceso de consolidación, por lo que surge la necesidad de discutir la formación de docentes de Educación Rural en el ámbito académico de nuestro país, centrándose en sus contribuciones al desarrollo rural y a la sociedad nacional. así como para superar procesos de exclusión sociohistórica para la educación de estas materias. ¿Cómo organizan los LEdoC con calificaciones en Ciencias Naturales el trabajo político-pedagógico y curricular por área en la formación inicial del profesorado? Para responder la pregunta, utilizamos las técnicas de análisis documental de los Proyectos PolíticoPedagógicos de los cursos de Licenciatura en Educación Rural con calificación en Ciencias Naturales en Brasil. Nuestra intención con estos análisis no es proponer una forma correcta o incorrecta de capacitar a los docentes en el campo o hacer comparaciones entre las APP de los cursos analizados, sino comprender cómo estos procesos de capacitación, aunque sean parcialmente, contribuyen al fortalecimiento de la educación rural.

Palabras clave: Formación docente. Entrenamiento por área. Plan de estudios.

Data de recebimento: $10 / 08 / 2020$

Data de aprovação: 20/12/2020

\title{
1 - INTRODUÇÃO
}

A sociedade prevalece sendo regida pela desigualdade, na qual, poder, saber e palavra não são conduzidos com equidade, mas distribuídos hierarquicamente de diferentes modos, repartidos de acordo com a divisão social do trabalho. Dessa forma, são poucos os que possuem o direito de dizer a palavra, de garantir a "verdade" e apresentar um conhecimento "legítimo". Na verdade, existimos em um mundo social governado pelos interesses de senhores 
do poder que, através de um Estado de democracia restrita, decidem e definem normas, regras e direitos da vida coletiva, as quais devem ser obedecidas pelos demais (BRANDÃO, 2012).

Nesse contexto é notável o posicionamento da escola diante desse processo de dominação/subordinação social. A escola tem sido instrumento de propagação das relações em sociedade, tem se tornado cada vez mais seletiva, segregadora e marginalizadora. Isso acontece na medida em que a escola desenvolve a função de adaptar e ajustar os educandos à sociedade, a partir de dons, talentos e aptidões individuais; de "compensar" os déficits socioculturais, porque "alguns" alunos são carentes e privados de cultura, "sem cultura"; de tratar a diferença como deficiência. Além disso, o problema é que o fracasso escolar ${ }^{4}$ é justamente característica dos alunos pertencentes às camadas desfavorecidas ${ }^{5}$ e esse efeito acentua e legitima as desigualdades sociais (SOARES, 2017).

Podemos ver a luta das camadas populares em nossa sociedade por reconhecimento de suas identidades, por direitos, respeito e pela chance de se viver mais dignamente. Diante disso surge a Educação do Campo, como resultado da pressão e das demandas dos trabalhadores e trabalhadoras do Campo, dos Movimentos Sindicais e Sociais. O trabalho em questão apresenta reflexões sobre a formação de professores em Educação do Campo, ressaltando a importância do Curso de Licenciatura em Educação do Campo (LEdoC) como instrumento de luta por uma Educação Básica que valorize a identidade do povo campesino e atenda suas necessidades enquanto sujeitos de direitos.

A Licenciatura em Educação do Campo (LEdoC) ainda é um curso em consolidação, com implantação recente, surge a necessidade de discutir a formação de professores da Educação do Campo no âmbito acadêmico de nosso país, tendo como foco suas contribuições para o desenvolvimento rural e para a sociedade nacional, bem como para a superação de processos de exclusão socio-históricos para educação desses sujeitos. Vale ressaltar que, no Brasil, temos 46 seis LEdoCs: 4 são considerados cursos-pilotos (UFMG, UnB, UFBA e UFS) e as demais são advindas do Edital n. 02/2012 - SESU/SETEC/SECADI/MEC, de 31 de agosto de 2012, Chamada Pública para seleção de Instituições Federais de Educação Superior - IFES e de Institutos Federais de Educação, Ciência e Tecnologia - IFET, para criação de cursos de Licenciatura em Educação do Campo, na modalidade presencial. Esses cursos distinguem-se em quatro áreas de conhecimento: Linguagens; Ciências Humanas e Sociais; Ciências da Natureza e Matemática; e Ciências Agrárias (MOLINA; SÁ, 2012). Isso é um diferencial quando se compara com as Licenciaturas disciplinares, posto que um dos desafios da Educação do Campo é "a ruptura com as tradicionais visões fragmentadas do processo de produção de conhecimento, com a disciplinarização da complexa realidade socioeconômica do meio rural na atualidade" (MOLINA; SÁ, 2012, p. 469). A formação por

4 Magda Soares $(2017$, p. 133,134) apresenta que "por fracasso escolar deve-se entender tanto fracasso na escola quanto fracasso da escola. A expressão fracasso na escola põe o foco nos alunos, em seu insucesso no seu processo de escolarização [...]. Grande parte desse fracasso na escola é consequência do fracasso da escola brasileira, resultante de políticas públicas ausentes ou ineficientes".

5 Usamos a definição de Magda Soares (2017), que emprega o termo camadas desfavorecidas para designar os indivíduos ou grupo de indivíduos que constituem uma camada qualificada "pelo critério de privação de bens, de benefícios, de adequadas condições econômicas, sociais, culturais". O termo camadas populares é empregado como sinônimo de camadas desfavorecidas. 
áreas de conhecimento busca superar essa centralidade na organização curricular por disciplinas, por meio de uma abordagem interdisciplinar e contextualizada dos conhecimentos científicos já conquistados historicamente com recortes da realidade no campo.

Como forma de delimitar nosso estudo, buscamos compreender como as LEdoCs com habilitação em Ciências da Natureza $(\mathrm{CN})$ organizam o trabalho político-pedagógico por área na formação inicial de professores. Por conseguinte, o objetivo é analisar a organização político-pedagógica e curricular dos cursos de Licenciatura em Educação do Campo (LEdoC) com habilitação em Ciências da Natureza $(\mathrm{CN})$ na formação de professores mediante o atendimento dos princípios da Educação do Campo.

\section{2 - METODOLOGIA}

Buscando assegurar a construção dos dados para atingir o objetivo principal do trabalho, utilizamos as técnicas da análise documental dos Projetos Político-Pedagógicos (PPPs) dos cursos de Licenciatura em Educação do Campo (LEdoC) com habilitação em Ciências da Natureza no Brasil. A escolha desses documentos deve-se ao fato de entendermos os PPPs como essenciais para a institucionalização e consolidação dos cursos em análise. E, ainda, concordamos com Farias e Faleiro (2019, p. 129) ao afirmarem que:

O PPP surge enquanto alternativa para se vislumbrar possibilidades, formas e estratégias para resolver, debater e materializar questões que se caracterizam como problemáticas no processo educativo. Vai além de uma lista de planos e atividades, é um processo vivenciado nos diversos momentos da instituição, na busca por uma direção. É uma ação com intencionalidade, de um processo coletivo na co-responsabilização dos diversos sujeitos que compõem a dinâmica educativa, levando em consideração tensões locais, nacionais e globais (VEIGA, 2007). Fagundes (2009) discorre sobre o PPP enquanto instrumento de mediação entre as produções sociais e pedagógicas.

Sobre o universo da pesquisa, dos quarenta e dois cursos de Licenciaturas em Educação do Campo provenientes do Edital n. 02/2012, optamos por trabalhar apenas com as Instituições de Ensino Superior que ofertam os cursos com habilitação em Ciências da Natureza por ser uma recomendação, preferência, dessa mesma Chamada Pública, a fim de atender a demanda de docentes habilitados nesta área nas escolas rurais. A Figura 1 indica apenas dezoito cursos no território brasileiro. 
Figura 1 - Licenciaturas em Educação do Campo com habilitação em Ciências da Natureza no Brasil.

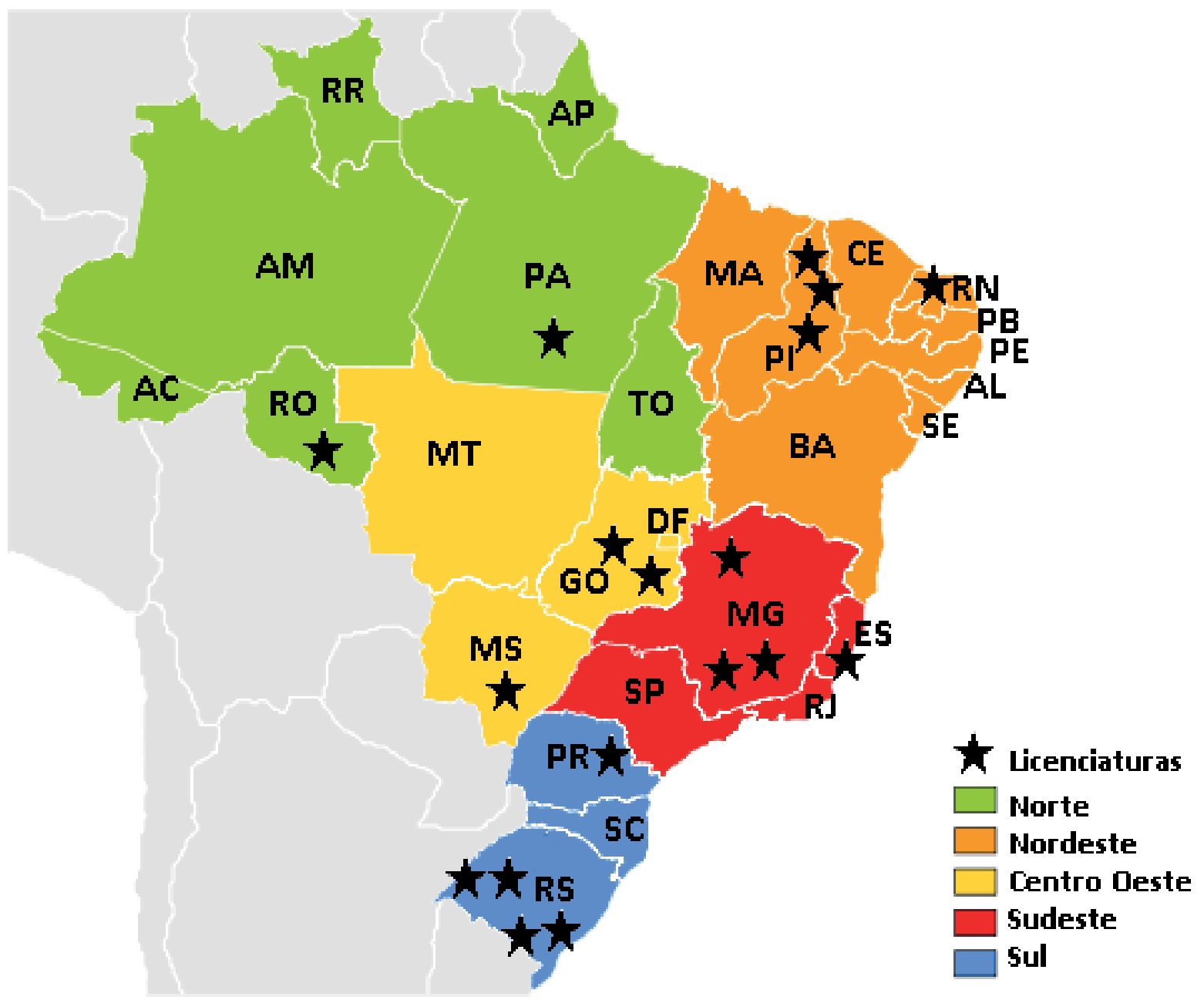

Fonte: FARIAS; FALEIRO, 2019.

Dos 18 cursos, analisamos cinco PPPs, sendo um de cada IES referente a uma região geográfica do país. Os critérios de seleção das IES, no ano de 2018, foram os seguintes:

- Serem cursos ofertados em Universidades, considerando apenas um modelo de trabalho institucional (13 cursos).

- Possuírem o PPP disponível no site oficial das Universidades (9 cursos).

Como a amostragem ainda era grande foi adotado alguns parâmetros específicos para a escolha de uma IES por região geográfica do Brasil: Para as regiões Norte, Nordeste e Sudeste foi levada em consideração a página do curso que apresentava melhor estruturação e informações disponíveis. Para a região Centro-oeste, os pesquisadores não possuírem nenhum vínculo com a instituição. E, para a região Sul, escolhemos a instituição que está inserida em um assentamento, o que não é a realidade das demais LEdoCs. O Quadro 1 apresenta as LEdoCs selecionadas para este estudo e indica como os PPPs foram identificados: letra "P" seguida de um número. 
Quadro 1 - Identificação das cinco Universidades selecionadas para análise do PPP de suas licenciaturas em Educação do Campo com habilitação em Ciências da Natureza.

\begin{tabular}{|c|c|c|c|}
\hline $\begin{array}{c}\text { Região } \\
\text { geográfica }\end{array}$ & Universidade & Estado & Identificação \\
\hline Norte & Universidade Federal de Rondônia (UNIR) & Rondônia & P-1 \\
\hline Nordeste & $\begin{array}{c}\text { Universidade Federal Rural do Semiárido } \\
\text { (UFERSA) }\end{array}$ & Rio Grande do Norte & P-2 \\
\hline Centro-Oeste & $\begin{array}{c}\text { Universidade Federal da Grande } \\
\text { Dourados (UFGD) }\end{array}$ & Mato Grosso do Sul & P-3 \\
\hline Sudeste & $\begin{array}{c}\text { Universidade Federal do Triângulo } \\
\text { Mineiro (UFTM) }\end{array}$ & Minas Gerais & P-4 \\
\hline Sul & $\begin{array}{c}\text { Universidade Federal da Fronteira do Sul } \\
\text { (UFFS) }\end{array}$ & Santa Catarina & P-5 \\
\hline
\end{tabular}

Fonte: Elaborado para o presente estudo (2020).

Com a definição das cinco IES e com a coleta do PPP de suas licenciaturas em Educação do Campo habilitação em Ciências da Natureza, fizemos uso da Análise de Conteúdo para tratarmos os nossos dados. Apesar de esse método ser marcado pelos "[...] postulados positivistas para os quais o rigor científico invocado é o da medida, objetividade, neutralidade e quantificação" (FRANCO, 2018, p. 9), destacamos que a referida autora traz a perspectiva de realizar uma Análise de Conteúdo baseado em "uma abordagem metodológica crítica e epistemologicamente apoiada numa concepção de ciência que reconhece o papel ativo do sujeito na produção do conhecimento" (p. 10).

\section{3 - RESULTADOS E DISCUSSÃO}

Dos cinco PPPs analisados, todos os cursos de LEdoCs são ofertados com duração de quatro anos, que é uma definição presente em vários pareceres e resoluções do Conselho Nacional de Educação (CNE), podendo ser acessados diretamente no site do Ministério da Educação (MEC) ${ }^{6}$.

O Edital n. 02/2012 ainda afirma que para concorrer a esta seleção

todos os Projetos Político Pedagógico de cursos deverão cumprir os critérios estabelecidos pela SESU/SETEC/SECADI, conforme estabelecido no Formulário de Apresentação de Projeto Político Pedagógico, anexo I, bem como estar em consonância com o Programa PRONACAMPO e os marcos legais da Educação do Campo (p. 2, grifos do documento). 
O Programa PRONACAMPO foi implementado por causa das "reivindicações históricas destas populações [do Campo e quilombolas] quanto à efetivação do direito à educação" [BRASIL, 2013, p. 2], objetivando

Disponibilizar apoio técnico e financeiro aos Estados, Municípios e Distrito Federal para a implementação da Política de Educação do Campo, visando à ampliação do acesso e a qualificação da oferta da Educação Básica e Superior, por meio de ações para a melhoria da infraestrutura das redes públicas de ensino, a formação inicial e continuada de professores, a produção e disponibilização de material específico aos estudantes do Campo e quilombolas, em todas as etapas e modalidades de ensino (p. 3)

Um dos eixos e ações do PRONACAMPO é/foi a formação inicial de professores para atuação nos anos finais do Ensino Fundamental e no Ensino Médio, o que caracteriza a implantação dos novos cursos de LEdoCs - PROCAMPO - selecionados pelo Edital n. 02/2012 e divulgados pela Portaria n. 72/2012. Os PPPs analisados no presente estudo são provenientes das propostas aprovadas no Processo Seletivo.

O Edital n. 02/2012 (BRASIL, 2012, p. 2-3) continua pontuando o que os PPPs deveriam apresentar:

- Considerar a realidade social e cultural específica das populações a serem beneficiadas;

- Prever os critérios e instrumentos para uma seleção específica a fim de contribuir para o atendimento da demanda por formação superior dos professores das escolas do Campo;

- Apresentar a organização curricular por etapas equivalentes a semestres regulares cumpridas em Regime de Alternância entre Tempo-Escola e Tempo-Comunidade;

- Apresentar diagnóstico da demanda no âmbito do Ensino Fundamental e do Ensino Médio nas comunidades a serem beneficiadas pelo projeto, bem como perfil e características sociais, culturais e econômicas de suas populações;

- Apresentar Currículo organizado de acordo com áreas de conhecimento previstas para a docência multidisciplinar, sendo que a recomendação e preferência era pelas habilitações em Ciências da Natureza para atendimento da demanda de professores nas escolas rurais;

- O coordenador deverá dispor de agenda para participar de reuniões técnicas (oficinas, seminários e outros eventos) convocados pela SECADI.

Além disso, no item 4.1.3 do edital, é especificado que

Os Projetos Político-Pedagógicos deverão contemplar os seguintes itens: apresentação, justificativa, objetivos, perfil desejado do formando [perfil do egresso], papel dos docentes, estratégias pedagógicas, Currículo (objetivos do Currículo, estrutura ou matriz curricular, etapas - identificação das etapas, objetivos das etapas, conteúdo programático, divido em unidades e subunidades, bibliografia básica e complementar), avaliação e acompanhamento das etapas e cronograma de execução. 
Desses critérios, observamos que os PPPs discutidos nesse estudo apresentam estrutura semelhante ao que é solicitado nesse edital, conforme podemos observar no Quadro 2.

Quadro 2 - Estrutura dos PPPs das Licenciaturas em Educação do Campo com habilitação em Ciências da Natureza das cinco Universidades selecionadas.

\begin{tabular}{|c|c|}
\hline PPP (ano) & Estrutura \\
\hline P-1 (2014) & $\begin{array}{l}\text { Apresentação; } \\
\text { 1. Contextualização; } \\
\text { 2. Organização didático-pedagógica; } \\
\text { 3. Estrutura administrativa e acadêmica do curso; } \\
\text { 4. Infraestrutura; } \\
\text { 5. Bibliografia; } \\
\text { Anexos }\end{array}$ \\
\hline P-2 (2013) & $\begin{array}{l}\text { 1. Dados cadastrais do proponente; } \\
\text { 2. Elaboração do projeto pedagógico (projeto do curso); } \\
\text { 3. Políticas de acesso; } \\
\text { 4. Plano geral de implementação do curso; } \\
\text { 5. Referências. }\end{array}$ \\
\hline P-3 (2017) & $\begin{array}{l}\text { 1. Introdução; } \\
\text { 2. Identificação do curso; } \\
\text { 3. Organização didático-pedagógica; } \\
\text { 4. Corpo docente e tutorial; } \\
\text { 5. Infraestrutura; } \\
\text { 6. Referências }\end{array}$ \\
\hline P-4 (2014) & $\begin{array}{l}\text { Identificação do curso; } \\
\text { Preâmbulo; } \\
\text { Fundamentação legal; } \\
\text { 1. Apresentação do projeto pedagógico; } \\
\text { 2. Histórico da UFTM e a identidade institucional; } \\
\text { 3. Histórico do curso e justificativa da necessidade social e econômica; } \\
\text { 4. Abrangência do curso no ensino, na pesquisa e na extensão; } \\
\text { 5. Administração acadêmica do curso; } \\
\text { 6. Concepção do curso; } \\
\text { 7. Organização curricular; } \\
\text { 8. Metodologia de ensino e aprendizagem; } \\
\text { 9. Sistema de avaliação; } \\
\text { 10. Incorporação das novas tecnologias educacionais ao ensino de graduação; } \\
\text { 11. Medidas de consolidação do curso; } \\
\text { 12. Políticas de acompanhamento aos alunos egressos; } \\
\text { 13. Ementas, conteúdos programáticos e bibliografias dos componentes curriculares; } \\
\text { Anexos }\end{array}$ \\
\hline
\end{tabular}




\begin{tabular}{|l|l|}
\hline PPP (ano) & \multicolumn{1}{c|}{ Estrutura } \\
\hline & $\begin{array}{l}\text { 1. Dados gerais do curso; } \\
\text { 2. Histórico institucional; } \\
\text { 3. Equipe de elaboração e acompanhamento do PPC; } \\
\text { 4. Justificativa da criação do curso; } \\
\text { 5. Referenciais orientadores; } \\
\text { 6. Objetivos do curso; } \\
\text { 7. Perfil do egresso; } \\
\text { 8. Organização curricular; } \\
\text { 9. Processo pedagógico e de gestão do curso e processo de avaliação do ensino e aprendizagem; } \\
\text { 10. Autoavaliação do curso; } \\
\text { 11. Articulação entre ensino, pesquisa e extensão; } \\
\text { 12. Perfil docente (competências, habilidades, comprometimento, entre outros) e } \\
\text { processo de qualificação; } \\
\text { 13. Quadro de pessoal docente; } \\
\text { 14. Infraestrutura necessária ao curso; } \\
\text { 15. Anexos; } \\
\text { Referências. }\end{array}$ \\
\hline
\end{tabular}

Fonte: Elaborado para o presente estudo (2020).

É importante evidenciarmos que os PPPs analisados são os que estavam disponibilizados nos sites institucionais de cada Universidade e, como podemos constatar, não estavam atualizados no momento da consulta, com exceção de P-4, que levando em consideração a data da busca (primeiro semestre de 2018), foi o mais atual. Aliás, dois PPPs, P-1 e P-2, apresentam termos que direcionam para supormos que a eventualidade de ser o documento encaminhado ao Ministério da Educação em atendimento ao Edital de seleção n. 02/2012 da SESU/SETEC/SECADI/MEC, de 31 de agosto de 2012. A seguir expomos alguns desses trechos:

Neste espaço estão implantados os laboratórios de solos, informática, biologia geral, genética, cinco salas de aula, laboratório de parasitologia, e tanques de piscicultura, sendo que essa infraestrutura poderá ser colocada à disposição do curso de Licenciatura em Educação do Campo ao ser implantado (P-1, 2014, p. 9, grifos nossos).

Pode-se considerar que o processo de implementação do Curso tem o seu início com a publicação desta chamada quando, desde então, um grupo de docentes da UFERSA passou a se reunir para se articular no sentido da construção desta proposta de Projeto Político Pedagógico. Dentro dos limites e dificuldades impostos por nossas atividades cotidianas na Universidade, a proposta foi construída e será encaminhada à SECADI/MEC (P-2, 2013, p. 76 , grifos nossos).

A constatação de que os projetos não foram atualizados e ainda trazem traços da proposta padrão que concorreu ao edital de seleção, mostram o quanto é preciso assumir como desafio o construir estruturas de trabalho mais coerentes, responsáveis e transformadoras. 
Uma observação interessante é que P-2 contém até o cronograma de execução, que especifica ações para implantação do curso de LEdoC, prevendo que em 2016 já seria o ingresso da sexta turma, sendo as defesas de TCC da primeira turma esperada para 2017/1, mesmo assim, esse era o documento disponibilizado no site da instituição.

Acrescentamos que apenas um desses PPPs assumem a orientação teórica e política do materialismo histórico-dialético para o trabalho pedagógico escolar: P-1, como podemos observas nas citações abaixo:

A fundamentação filosófica do curso de Licenciatura em Educação do Campo tem por base a concepção do materialismo histórico e dialético em que prima por compreender o contexto da realidade vivencial dos discentes, a totalidade dos fatos e fenômenos sociais, dentre outros aspectos relevantes que são considerados nesta perspectiva (P-1, 2014, p. 14, grifo nosso).

Compreende-se que a concepção do Materialismo Histórico e Dialético sustenta a orientação filosófica deste curso, por se tratar de abordagem que se preocupa com as interconexões dos saberes nas diversas áreas do conhecimento e disciplinas do Currículo de ensino, buscando compreender e explicar a objetividade da natureza e da história e reciprocidade de influências entre a história da sociedade e a história da natureza (P-1, 2014, p. 15).

Assim, o Materialismo Histórico e Dialético é a teoria por excelência de base epistemológica para a orientação da Alternância Pedagógica na Licenciatura da Educação do Campo (P-1, 2014, p. 16).

Em P-1, sua abordagem é fundamentada pelo diálogo com autores e obras importantes do materialismo histórico-dialético, como "A dialética da natureza", de Engels, "A ideologia alemã", de Marx e Engels, e outras obras de Marx. Bezerra Neto e Bezerra (2010, p. 253) defendem que "através deste método de análise devemos partir sempre do particular para o geral, partindo de um dado empírico, concreto, factual, daí sua importância para compreender os movimentos de luta pela terra e o processo educacional por estes desenvolvidos".

Apesar de não se posicionarem sobre o aspecto filosófico adotado, P-4 e P-5 deixam subentendidos que também adotam o materialismo histórico-dialético. P-4 afirma uma abordagem dialética: "Ao se considerar a realidade humana e social atual, caracterizada pelo avanço tecnológico e a informação instantânea, pela globalização e pela abordagem dialética de educação, será levada em conta, na metodologia do curso, a relação dialética entre teoria/ prática/teoria" (P-4, 2014, p. 118-119, grifos nossos). Enquanto P-5 menciona um princípio marxista que nos direciona ao materialismo:

Como estratégia para que este processo se consolide de forma cumulativa, os Seminários Integradores serão propostos para que avancem no sentido de envolver situações cada vez mais complexas e abrangentes, partindo de uma compreensão inicial do próprio sujeito para a compreensão cada vez mais ampliada de mundo (P-5, 2013, p. 42, grifo nosso). 
Posteriormente no documento, cita um dos teóricos principais do materialismo, Marx:

Para romper com a lógica que tem por base a subserviência ao capital, é preciso instaurar um projeto de formação-educação que facilite aos sujeitos colocarem-se em movimento, sendo capazes de pensar alternativas que criem novas relações a partir das condições existentes na sociedade (MARX), assumindo princípios omnilaterais, totalizadores (P-5, 2013, p. 124).

Assim, podemos sinalizar que para essa corrente filosófica é interessante relacioná-la à perspectiva freireana, uma vez que, segundo Bezerra Neto e Bezerra (2010, p. 264),

Toda a pedagogia do Movimento dos Trabalhadores Rurais Sem Terra tem por base a Pedagogia de Paulo Freire, neste sentido, é Roseli Caldart, quem afirma que existe uma relação entre a Pedagogia do Movimento e a Pedagogia do Oprimido (teorizada por Paulo Freire), dado que segundo ela, ambas são materializações históricas da Pedagogia da Práxis e por isso, a Pedagogia do Movimento também é herdeira da Pedagogia do Oprimido.

A Pedagogia de Paulo Freire tem por base o existencialismo cristão, o qual acredita que "o homem se faz no mundo, ao longo de sua vida, através de suas experiências, seus conflitos suas conquistas e derrotas, não existindo uma essência do que seja o ser humano. Assim cada indivíduo é um ser particular, que constrói sua própria essência" (BEZERRA NETO; BEZERRA, 2010, p. 265). Porém, há uma contradição nessas teorias, dizemos em relação ao marxismo e ao existencialismo, conforme discutido pelos autores supracitados:

O marxismo se diferencia do existencialismo, por entender que a realidade existe independentemente da consciência sobre ela, dado que o homem tem uma essência, que é sua capacidade de transformar o mundo e criar, em última instância, seu próprio mundo. Já para o existencialista a realidade deriva da consciência sobre o mundo, a ponto de os filósofos existencialistas afirmarem que a "existência precede a essência" (p. 266).

Os autores (p. 265-266) ainda afirmam que é justamente essa relação contraditória que justifica o método do materialismo histórico-dialético para a Educação do Campo, considerando que

Como a realidade é contraditória, histórica e dialética e não apenas uma questão de escolhas de um cientista e/ou de um filósofo, necessitamos de um método para entendê-la. Como a realidade é material, entendemos que o melhor método para o seu entendimento é o materialismo histórico e dialético, que vê a realidade como materialista histórica e dialética, buscando entendê-la em toda sua totalidade e complexidade.

Tendo isso em consideração, também observamos nos PPPs que todos adotam perspectivas humanistas de educação, principalmente a pedagogia de Paulo Freire. P-1 (2014, p. 19) declara: 
A orientação epistemológica que direciona o curso de Licenciatura em Educação do Campo inspira uma cumplicidade entre educandos e educadores no ato de ensinar e aprender. Tal afinidade rompe com a concepção tradicional, vista por Freire como concepção bancária da educação, em que a relação vertical que se estabelece entre ambos, nega a essência da existência do homem, em que a aprendizagem acontece em diferentes espaços da existência em que o processo produtivo tem lugar privilegiado.

P-2 (2013, p. 27) não apresenta um argumento explícito sobre esse aspecto pedagógico, mas direciona para tal ao afirmar que "as estratégias pedagógicas deverão pautar-se na ideia de que o foco da educação é o/a educando/a, como sujeito histórico, de forma contextualizada". Já P-3 (2017, p. 14-15) posiciona que

[...] o PPP toma como princípios a dinâmica da Alternância, a relação da organicidade com os Movimentos Sociais e o contexto local, considerando como marco teórico/metodológico, entre outas, as perspectivas humanistas de educação (em especial Vigotski, Gramsci e Freire). A partir destas referencias concebe-se uma relação pedagógica onde os educandos não são pessoas genéricas, mas vinculadas às comunidades camponesas, inseridas nas práticas pedagógicas locais - prática que será o ponto de partida do processo formativo.

P-3 (2017, p. 83-84) reitera que "as atividades deverão respeitar os princípios da educação libertadora por meio de uma vivência coletiva, pautada no diálogo na troca de experiência e de saberes, no respeito mútuo, na discussão das dificuldades, nos estudos em grupo para a realização das atividades previstas". P-4 (2014, p. 41), da mesma forma defende as ideias de Freire,

A formação do educador do Campo deve ser feita na perspectiva da educação libertadora, amparada nos princípios defendidos por Freire, que entende ser papel do educador contribuir para a inserção dos sujeitos oprimidos num contexto em que estes se coloquem no mundo de maneira ativa, consciente e questionadora. Por isso, esta proposta encontra respaldo em Freire (1977, 1979), pela necessidade de se estabelecer um diálogo com os sujeitos acerca da educação na perspectiva da práxis libertadora e dialógica.

Outro ponto relevante citado por P-4 (2014, p. 42) é uso da práxis educativa como meio para a consciência de classe:

A práxis educativa (FREIRE, 1979), união 'teoria-prática', será estimulada através da reflexão da prática por meio da teoria, visando criar condições para que os sujeitos alcancem um nível de amadurecimento e de consciência de sua condição, das lutas de classe e que percebam que a conquista da terra não basta, que é necessário, portanto, desencadear outras lutas para que tenham condições de vida reais e dignas (GONZAGA, 2009). 
Por fim, P-5 (2013, p. 31) defende que, na perspectiva freireana, "o conhecimento exige uma presença curiosa do sujeito em face do mundo, requerendo a ação transformadora sobre a realidade, demandando a busca constante e reclamando a reflexão crítica de cada um sobre o ato mesmo de conhecer".

Como foram analisados PPPs das LEdoCs com habilitação em Ciências da Natureza (CN), para uma melhor compreensão dessa organização curricular, faz-se necessário analisar a carga horária $(\mathrm{CH})$ das disciplinas relacionadas à área, assim no Quadro 3 apresentamos a organização curricular desses documentos, definindo o que cada PPP traz sobre o núcleo/ domínio e a carga horária $(\mathrm{CH})$ correspondente. Vale ressaltar que os componentes curriculares em P-1, P-2, P-3 e P-4 estão organizados em núcleos. P-5 organiza por domínios.

Quadro 3 - Organização e definição dos componentes curriculares apresentada nos PPPs das cinco LEdoCs brasileiras selecionadas.

\begin{tabular}{|c|c|c|c|}
\hline & Organização curricular & Definição & CH (\%) \\
\hline \multirow{3}{*}{ P-1 } & $\begin{array}{l}\text { Núcleo comum } \\
\text { obrigatório }\end{array}$ & $\begin{array}{l}\text { "estão as disciplinas que permitem embasamento teórico prático" } \\
\text { (p. 42) }\end{array}$ & $\begin{array}{c}800 \mathrm{~h} \\
( \pm 24 \%)\end{array}$ \\
\hline & $\begin{array}{l}\text { Núcleo de estudos } \\
\text { pedagógicos específicos }\end{array}$ & $\begin{array}{l}\text { Estão as disciplinas específicas da área de habilitação e } \\
\text { correspondem aos conhecimentos de Biologia, Química e Física }\end{array}$ & $\begin{array}{l}1760 \mathrm{~h} \\
( \pm 52 \%)\end{array}$ \\
\hline & $\begin{array}{l}\text { Núcleo de formação } \\
\text { integrador }\end{array}$ & $\begin{array}{l}\text { "estão as disciplinas destinadas à formação pedagógica para o } \\
\text { exercício da profissão docente" (p. 42) }\end{array}$ & $\begin{array}{c}800 \mathrm{~h} \\
( \pm 24 \%)\end{array}$ \\
\hline \multirow{3}{*}{ P-2 } & Núcleo de estudos comuns & $\begin{array}{l}\text { "estão inseridas disciplinas nas áreas de Linguagens e Códigos, } \\
\text { Ciências Agrárias, Matemática, Ciências Humanas e Sociais (p. 29) }\end{array}$ & $\begin{array}{l}1605 \mathrm{~h} \\
(50 \%)\end{array}$ \\
\hline & $\begin{array}{l}\text { Núcleo de atividades } \\
\text { integradoras }\end{array}$ & $\begin{array}{l}\text { "estão inseridas as componentes de pesquisa, práticas pedagógicas, } \\
\text { métodos de organização e educação comunitária, seminários } \\
\text { integradores, estágios curriculares supervisionados e trabalho de } \\
\text { conclusão de curso" (p. 29) }\end{array}$ & $\begin{array}{c}975 \mathrm{~h} \\
( \pm 30 \%)\end{array}$ \\
\hline & $\begin{array}{l}\text { Núcleo de estudos } \\
\text { específicos }\end{array}$ & $\begin{array}{l}\text { Estão as componentes que correspondem à habilitação Ciências } \\
\text { da Natureza }\end{array}$ & $\begin{array}{c}630 \mathrm{~h} \\
( \pm 20 \%)\end{array}$ \\
\hline \multirow{3}{*}{$\mathrm{P}-3$} & $\begin{array}{l}\text { Núcleo de estudos de } \\
\text { formação geral, áreas } \\
\text { específicas e interdiscipli- } \\
\text { naridade }\end{array}$ & $\begin{array}{l}\text { "campo educacional, seus fundamentos e metodologias, e das } \\
\text { diversas realidades educacionais" (p. 17) }\end{array}$ & $\begin{array}{l}1680 h \\
( \pm 49 \%)\end{array}$ \\
\hline & $\begin{array}{l}\text { Núcleo de } \\
\text { aprofundamento e } \\
\text { diversificação das áreas de } \\
\text { atuação profissional }\end{array}$ & $\begin{array}{l}\text { "conteúdos específicos e pedagógicos, priorizadas pelo projeto } \\
\text { pedagógico das instituições, em sintonia com os sistemas de } \\
\text { ensino" (p. 18) }\end{array}$ & $\begin{array}{c}1060 \mathrm{~h} \\
( \pm 31 \%)\end{array}$ \\
\hline & $\begin{array}{l}\text { Núcleo de estudos } \\
\text { integradores }\end{array}$ & $\begin{array}{l}\text { "para enriquecimento curricular" (p. 19), compreende os } \\
\text { seminários e estudos curriculares, atividades práticas e atividades } \\
\text { de comunicação e expressão }\end{array}$ & $\begin{array}{c}680 \mathrm{~h} \\
( \pm 20 \%)\end{array}$ \\
\hline
\end{tabular}




\begin{tabular}{|c|c|c|c|}
\hline \multirow{3}{*}{$\mathrm{P}-4$} & $\begin{array}{l}\text { Núcleo de estudos } \\
\text { formador }\end{array}$ & $\begin{array}{l}\text { "subsídios para a construção da formação intelectual, visando } \\
\text { a reafirmação da identidade cultural da comunidade do Campo, } \\
\text { articulando aspectos de docência, memória e práticas educativas } \\
\text { na Educação do Campo como principais elementos da formação } \\
\text { educador/licenciado" (p. 104) }\end{array}$ & $\begin{array}{c}1020 \mathrm{~h} \\
( \pm 30 \%)\end{array}$ \\
\hline & $\begin{array}{l}\text { Núcleo de estudos } \\
\text { específicos }\end{array}$ & $\begin{array}{l}\text { "Tem como objetivo possibilitar uma sólida formação teórico- } \\
\text { prática do licenciando, por meio da oferta de componentes } \\
\text { curriculares que objetivam o desenvolvimento de competências } \\
\text { e habilidades para a sua atuação como professor, conforme a } \\
\text { habilitação escolhida" (p. 104). São apresentadas as disciplinas } \\
\text { da habilitação em Ciências da Natureza }\end{array}$ & $\begin{array}{c}1080 \mathrm{~h} \\
( \pm 32 \%)\end{array}$ \\
\hline & $\begin{array}{l}\text { Núcleo de estudos } \\
\text { integrador }\end{array}$ & $\begin{array}{l}\text { Composto por Trabalho de Conclusão de Curso (TCC); atividades } \\
\text { práticas curriculares; estágio curricular supervisionado; atividades } \\
\text { acadêmico-científico-culturais }\end{array}$ & $\begin{array}{c}1260 \mathrm{~h} \\
( \pm 38 \%)\end{array}$ \\
\hline \multirow{9}{*}{$\mathrm{P}-5$} & Domínio comum & $\begin{array}{l}\text { "Os componentes curriculares do domínio comum buscam asse- } \\
\text { gurar que todos os estudantes da UFFS recebam uma formação ao } \\
\text { mesmo tempo cidadã, interdisciplinar e profissional, possibilitan- } \\
\text { do otimizar a gestão da oferta de disciplinas pelo corpo docente } \\
\text { e, como consequência, ampliar as oportunidades de acesso à co- } \\
\text { munidade, com ênfase em fundamentos ontológicos, histórico-so- } \\
\text { ciais e ético-epistemológicos" (p. 49) }\end{array}$ & $\begin{array}{l}540 \mathrm{~h} \\
(16 \%)\end{array}$ \\
\hline & Domínio conexo & $\begin{array}{l}\text { "compõe-se de um conjunto de disciplinas da área pedagógica, as } \\
\text { quais têm por finalidades situar e habilitar o acadêmico do curso } \\
\text { para a prática docente na área de formação prevista (Ciências da } \\
\text { Natureza)" (p. } 50 \text { ) }\end{array}$ & $\begin{array}{l}300 \mathrm{~h} \\
(9 \%)\end{array}$ \\
\hline & Domínio específico & "abordar as temáticas próprias do curso" (p. 51) & $\begin{array}{c}360 \mathrm{~h} \\
(10,5 \%)\end{array}$ \\
\hline & Área de formação & $\begin{array}{l}\text { "têm como objetivo o tratamento dos conhecimentos necessários } \\
\text { para a formação do professor para atuar no Ensino Fundamental } \\
\text { e Médio, que tem como foco a área de Ciências da Natureza } \\
\text { (Biologia, Física e Química)" (p. 52) }\end{array}$ & $\begin{array}{c}855 \mathrm{~h} \\
(25,5 \%)\end{array}$ \\
\hline & $\begin{array}{l}\text { Trabalho de conclusão de } \\
\text { curso }\end{array}$ & & $\begin{array}{c}120 \mathrm{~h} \\
(3,5 \%)\end{array}$ \\
\hline & $\begin{array}{l}\text { Prática pedagógica como } \\
\text { componente curricular }\end{array}$ & Seminários integradores & $\begin{array}{c}420 \mathrm{~h} \\
(12,5 \%)\end{array}$ \\
\hline & Estágios & & $\begin{array}{l}405 \mathrm{~h} \\
(12 \%)\end{array}$ \\
\hline & $\begin{array}{l}\text { Componentes curriculares } \\
\text { optativos }\end{array}$ & Tópicos especiais & $\begin{array}{l}180 \mathrm{~h} \\
(5 \%)\end{array}$ \\
\hline & $\begin{array}{l}\text { Atividades curriculares } \\
\text { complementares }\end{array}$ & & $\begin{array}{l}210 \mathrm{~h} \\
(6 \%)\end{array}$ \\
\hline
\end{tabular}

Fonte: Elaborado para o presente estudo (2020). 
Outra observação relevante é a carga horária total do curso, porque alguns deles integralizam-se com o cumprimento dos componentes curriculares dos núcleos, como é o caso de P-2, P-3 e P-4, que possuem 3.210 h, 3.420 h, 3.360 h, respectivamente. Já P-1 e P-5 se organizam diferentemente. $\mathrm{P}-1^{7}$ é estruturado de maneira que os componentes curriculares (disciplinas) compõem os núcleos básicos, como descrito no Quadro 3. Mas para a integralização do curso é distribuída em: $\mathrm{CH}$ de disciplinas - 3.360 h; $\mathrm{CH}$ de estágio - 400 h; $\mathrm{CH}$ de atividades complementares $-200 \mathrm{~h}$; seminários temáticos $-100 \mathrm{~h}$, totalizando 4.060 h. E, P-5 dedica-se 3.390 h à integralização do curso, distribuídas conforme apresentado.

Ainda, afirmamos que a $\mathrm{CH}$ das disciplinas dedicadas às Ciências da Natureza para os PPPs analisados é distribuída de maneira distinta em cada documento: P-1 destina $\pm 52 \%$ da sua $\mathrm{CH}$ de disciplinas para os estudos nessa área de habilitação; P-2, $\pm 20 \%$ de sua $\mathrm{CH}$ total; P-3, $\pm 49 \%$ da $\mathrm{CH}$ total; $\mathrm{P}-4, \pm 32 \%$ da $\mathrm{CH}$ total; P-5, 25,5\% da $\mathrm{CH}$ total. Entretanto, isso não quer dizer que essa $\mathrm{CH}$ é disposta integralmente às disciplinas de Biologia, Física e Química, conforme podemos observar no Quadro 4, que especifica os núcleos/domínio específicos da habilitação em Ciências da Natureza.

Quadro 4 - Especificação dos núcleos/domínio que são ofertadas as disciplinas da habilitação em Ciências da Natureza das cinco LEdoCs brasileiras selecionadas.

\begin{tabular}{|c|c|c|}
\hline & Núcleo/domínio & Disciplina \\
\hline \multirow{22}{*}{$\mathrm{P}-1$} & \multirow{22}{*}{ Núcleo de estudos pedagógicos específicos } & Biologia geral \\
\hline & & Geopolítica das migracões (optativa) \\
\hline & & Química I, II \\
\hline & & Física I, II \\
\hline & & Matemática aplicada ao ensino de Ciências da \\
\hline & & Natureza \\
\hline & & Histologia e Citologia \\
\hline & & Fundamentos teóricos e metodológicos da \\
\hline & & pesquisa em Ciências da Natureza \\
\hline & & Agricultura camponesa e sustentabilidade \\
\hline & & Bioquímica \\
\hline & & Os agrotóxicos e o meio ambiente \\
\hline & & Genética animal \\
\hline & & Genética vegetal \\
\hline & & Reprodução e embriologia animal \\
\hline & & Biofísica \\
\hline & & Ecologia \\
\hline & & Reprodução e embriologia vegetal \\
\hline & & Agricultura alternativa \\
\hline & & Bioética \\
\hline & & Manejo e usos do solo \\
\hline & & Biotecnologia e as necessidades humanas \\
\hline
\end{tabular}




\begin{tabular}{|c|c|c|}
\hline \multirow{10}{*}{$\mathrm{P}-2$} & \multirow{10}{*}{ Núcleo de estudos específicos } & Metodologia do Ensino das Ciências Naturais \\
\hline & & Fundamentos da matemática II \\
\hline & & Educação socioambiental \\
\hline & & Introdução ao estudo da química \\
\hline & & Instrumentação para o ensino de química \\
\hline & & Física na Educação Básica I, II \\
\hline & & Instrumentação para o ensino de física \\
\hline & & Biologia \\
\hline & & Olericultura e plantas medicinais \\
\hline & & Ambiente, tecnologia e sociedade \\
\hline \multirow{26}{*}{ P-3 } & \multirow{26}{*}{$\begin{array}{l}\text { Núcleo de estudos de formação geral, áreas } \\
\text { específicas e interdisciplinaridade }\end{array}$} & Biodiversidade e biomas brasileiros \\
\hline & & Biologia, biotecnologia e ensino de Ciências \\
\hline & & $\begin{array}{l}\text { Desenvolvimento humano, meio ambiente e } \\
\text { saúde }\end{array}$ \\
\hline & & Didática \\
\hline & & $\begin{array}{l}\text { Diversidade morfofisiológica dos seres vivos I, } \\
\text { II }\end{array}$ \\
\hline & & Educação socioambiental e sustentabilidade \\
\hline & & Energia e dinâmica nos ecossistemas \\
\hline & & Estatística aplicadas às questões do Campo \\
\hline & & Ferramentas matemáticas no ensino de Ciências \\
\hline & & Física aplicada à Educação do Campo \\
\hline & & Geociências \\
\hline & & História da África e afro-brasileira \\
\hline & & História indígena e educação étnico-racial \\
\hline & & Leitura e produção de textos \\
\hline & & LIBRAS \\
\hline & & Manejo ecológico dos sistemas de produção \\
\hline & & Meio ambiente e ecologia dos ecossistemas \\
\hline & & Meio ambiente e eletromagnetismo \\
\hline & & $\begin{array}{l}\text { Métodos e técnicas de pesquisa em Educação } \\
\text { do Campo }\end{array}$ \\
\hline & & \begin{tabular}{|l|} 
Políticas públicas em Educação \\
\end{tabular} \\
\hline & & Políticas públicas, direitos humanos e cidadania \\
\hline & & Princípios básicos da Educação Especial \\
\hline & & Psicologia da Educação \\
\hline & & Química Ambiental I, II \\
\hline & & Química aplicada à Educação do Campo \\
\hline & & Sociologia da Educação \\
\hline
\end{tabular}




\begin{tabular}{|c|c|c|}
\hline \multirow{15}{*}{$\mathrm{P}-4$} & \multirow{15}{*}{ Núcleo de estudos específicos } & Ecologia geral e estudo do meio \\
\hline & & Química e tecnologia do cotidiano \\
\hline & & Introdução à física \\
\hline & & Química do solo, da água e da atmosfera \\
\hline & & $\begin{array}{l}\text { Zoologia de invertebrados no contexto do } \\
\text { Campo }\end{array}$ \\
\hline & & $\begin{array}{l}\text { Fundamentos de mecânica e artefatos } \\
\text { tecnológicos do Campo }\end{array}$ \\
\hline & & Zoologia de vertebrados no contexto do Campo \\
\hline & & Fundamentos de termofísica e vida no Campo \\
\hline & & Química aplicada aos seres vivos \\
\hline & & Botânica geral \\
\hline & & Energia e temperatura na química \\
\hline & & $\begin{array}{l}\text { Eletricidade e eletromagnetismo no contexto do } \\
\text { Campo }\end{array}$ \\
\hline & & Genética e evolução \\
\hline & & Anatomia e fisiologia humana I, II \\
\hline & & Paleontologia \\
\hline \multirow{6}{*}{ P-5 } & \multirow{6}{*}{ Área de formação } & Fundamentos da matemática \\
\hline & & História e Filosofia das Ciências Naturais \\
\hline & & Biologia Geral \\
\hline & & Biologia na Educação Básica I, II, III, IV \\
\hline & & Física na Educação Básica I, II, III, IV \\
\hline & & Química na Educação Básica I, II, III, IV \\
\hline
\end{tabular}

Fonte: Elaborado para o presente estudo (2020). Legenda: Disciplinas da área CN (Biologia, Física e Química - em cor azul), disciplinas pedagógicas e/ou do campo educacional (em cor laranja); disciplinas relacionadas à realidade do Campo (em cor verde); às Ciências (em cor amarelo), de um modo geral; à Matemática (em cor vermelho).

Diante da breve análise, pois não era objetivo deste estudo analisar as ementas dos cursos, podemos supor que nesses núcleos/domínio são ofertadas, além das disciplinas relacionadas às $\mathrm{CN}$, disciplinas pedagógicas e/ou do campo educacional; disciplinas relacionadas à realidade do Campo; às Ciências, de um modo geral; à Matemática. Logo, conseguimos dimensionar a quantidade de horas que são dedicadas às disciplinas da área de habilitação (aqui estamos falando apenas das disciplinas específicas da área Ciências da Natureza):

- Cada disciplina específica de P-1 tem CH igual a 80 h, assim são destinadas 1.200 $\mathrm{h}$ do curso às $\mathrm{CN}$, sendo correspondente a 15 disciplinas;

- Cada disciplina específica de P-2 tem CH igual a 60 h, assim são destinadas 420 $\mathrm{h}$ do curso às $\mathrm{CN}$, sendo correspondente a 7 disciplinas;

- Cada disciplina específica de P-3 tem CH igual a 72 h, assim são destinadas 936 $\mathrm{h}$ do curso às $\mathrm{CN}$ sendo correspondente a 13 disciplinas;

- Em P-4, 8 disciplinas específicas têm CH igual a 75 h, as outras 7, 60 h, assim são destinadas $1.020 \mathrm{~h}$ do curso às $\mathrm{CN}$; 
- Cada disciplina específica de P-5 tem CH igual a 60 h, com exceção das disciplinas Biologia na Educação Básica IV, Física na Educação Básica IV e Química na Educação Básica IV, que possuem $\mathrm{CH}$ de 45 h. Assim, são destinadas 735 h do curso às $\mathrm{CN}$.

Dessa forma, temos valores reais da $\mathrm{CH}$ que é destinada à área de Ciências da Natureza: P-1 destina $\pm 29 \%$ da $\mathrm{CH}$ do curso às $\mathrm{CN}$; P-2, $\pm 13 \%$; P-3, $\pm 27 \%$; P-4, $\pm 30 \%$; $\mathrm{P}-5, \pm 21 \%$. Portanto, P-4, P-1 e P-3 são os cursos que distribuem uma maior $\mathrm{CH}$ para a área de habilitação em foco.

Para além dessa comparação, o Quadro 5 nos apresenta um enfoque nas disciplinas relacionadas às Ciências da Natureza classificadas em Biologia (em amarelo); Física (em vermelho); Química (em azul); Biologia e/ou Física (em laranja); Biologia e/ou Química (em verde); Física e/ou Química (em roxo). Nosso intuito foi identificar se os cursos analisados apresentam carga horária proporcional a cada disciplina dessa área de conhecimento ou se a formação é voltada especificadamente para alguma delas.

Quadro 5 - Classificação das disciplinas da área de CN em Biologia, Física e Química das cinco LEdoCs brasileiras selecionadas.

\begin{tabular}{|c|c|c|}
\hline & Núcleo/domínio & Disciplina \\
\hline \multirow{13}{*}{ P-1 } & \multirow{13}{*}{ Núcleo de estudos pedagógicos específicos } & Biologia geral \\
\hline & & Química I, II \\
\hline & & Física I, II \\
\hline & & Histologia e Citologia \\
\hline & & Bioquímica \\
\hline & & Os agrotóxicos e o meio ambiente \\
\hline & & Genética animal \\
\hline & & Genética vegetal \\
\hline & & Reproduçáo e embriologia animal \\
\hline & & Biofísica \\
\hline & & Ecologia \\
\hline & & Reproduçăo e embriologia vegetal \\
\hline & & Bioética \\
\hline \multirow{6}{*}{$\mathrm{P}-2$} & \multirow{6}{*}{ Núcleo de estudos específicos } & Introduçăo ao estudo da química \\
\hline & & Instrumentaçáo para o ensino de química \\
\hline & & Física na Educaçăo Básica I, II \\
\hline & & Instrumentaçấo para o ensino de física \\
\hline & & Biologia \\
\hline & & Olericultura e plantas medicinais \\
\hline
\end{tabular}




\begin{tabular}{|c|c|c|}
\hline \multirow{11}{*}{ P-3 } & \multirow{11}{*}{$\begin{array}{l}\text { Núcleo de estudos de formaçáo geral, áreas } \\
\text { específicas e interdisciplinaridade }\end{array}$} & Biodiversidade e biomas brasileiros \\
\hline & & Biologia, biotecnologia e ensino de Ciências \\
\hline & & Desenvolvimento humano, meio ambiente e saúde \\
\hline & & Diversidade morfofisiológica dos seres vivos I, II \\
\hline & & Energia e dinâmica nos ecossistemas \\
\hline & & Física aplicada à Educaçâo do Campo \\
\hline & & Manejo ecológico dos sistemas de produçâo \\
\hline & & Meio ambiente e ecologia dos ecossistemas \\
\hline & & Meio ambiente e eletromagnetismo \\
\hline & & Química Ambiental I, II \\
\hline & & Química aplicada à Educaçăo do Campo \\
\hline \multirow{14}{*}{ P-4 } & \multirow{14}{*}{ Núcleo de estudos específicos } & Ecologia geral e estudo do meio \\
\hline & & Química e tecnologia do cotidiano \\
\hline & & Introduçāo à física \\
\hline & & Química do solo, da água e da atmosfera \\
\hline & & Zoologia de invertebrados no contexto do Campo \\
\hline & & $\begin{array}{l}\text { Fundamentos de mecânica e artefatos } \\
\text { tecnológicos do Campo }\end{array}$ \\
\hline & & Zoologia de vertebrados no contexto do Campo \\
\hline & & Fundamentos de termofísica e vida no Campo \\
\hline & & Química aplicada aos seres vivos \\
\hline & & Botânica geral \\
\hline & & Energia e temperatura na química \\
\hline & & $\begin{array}{l}\text { Eletricidade e eletromagnetismo no contexto } \\
\text { do Campo }\end{array}$ \\
\hline & & Genética e evoluçăo \\
\hline & & Anatomia e fisiologia humana I, II \\
\hline \multirow{4}{*}{ P-5 } & \multirow{4}{*}{ Área de formaçâo } & Biologia Geral \\
\hline & & Biologia na Educaçăo Básica I, II, III, IV \\
\hline & & Física na Educaçāo Básica I, II, III, IV \\
\hline & & Química na Educaçăo Básica I, II, III, IV \\
\hline
\end{tabular}

Fonte: Elaborado para o presente estudo (2020).

Legenda: Biologia (em amarelo); Física (em vermelho); Química (em azul); Biologia e/ou Física (em laranja); Biologia e/ou Química (em verde); Física e/ou Química (em roxo).

Como resultado, a maioria dos cursos discutidos nesse estudo dão maior ênfase ao estudo de conteúdos relacionados à Biologia (P-1, $\pm 53 \% ; \mathrm{P}-3, \pm 54 \%$; P-4, 50\% e P-5, \pm $39 \%)$, com exceção apenas de P-2, que enfoca mais para a Física $( \pm 43 \%)$. Podemos inferir, sobre a maioria dos cursos terem maior $\mathrm{CH}$ para as disciplinas de Biologia, que seja por esta ser utilizada com mais frequência, principalmente na disciplina de Ciências no Ensino Fundamental. 
Para mais, em um estudo realizado por Almeida (2019), o autor faz um comparativo entre a $\mathrm{CH}$ das disciplinas de Química, Física e Biologia ministradas na LEdoC da UFGD e UFFS e a $\mathrm{CH}$ dos cursos de Licenciatura em Química, Física e Biologia oferecidos em ambas as IES, e conclui que a quantidade de horas trabalhadas na LEdoC é muito inferior ao que se é trabalhado na Licenciatura em Química, por exemplo, e argumenta:

Tal situação por sua vez, permite ao egresso de um curso de Licenciatura em Química, melhor aprofundamento sobre os conteúdos a serem trabalhados no ensino de Química, pois sua formação inicial o prepara para compreensão de assuntos mais complexos relacionados a essa área do saber, e que de certo modo, são necessários para o desenvolvimento de alguns conteúdos a nível fundamental e médio (ALMEIDA, 2019, p. 46).

Porém, o autor ressalta que a intenção desse viés de argumentação não é inferiorizar as LEdoCs com habilitação em CN, "e sim considerar que um melhor aprofundamento dos conteúdos curriculares dessas áreas, por meio do aumento da carga horária, permitiria ao futuro egresso melhor compreensão de conceitos e suas aplicações durante a abordagem no Ensino Fundamental e Médio" (ALMEIDA, 2019, p. 46). Isso porque para ele é importante nos preocupar "com uma formação que permita ao sujeito do campo, ter direito a vir para o urbano sem perdas ou agravamento do processo de subalternização e demérito já dado a esse sujeito" (ALMEIDA, 2019, p. 46).

A intenção dessa discussão sobre as $\mathrm{CH}$ não é contradizer a formação por área, haja vista que as IES estão formando professores/as por área e não por disciplinas. Contudo, este tipo de formação é complexo, além de habilitar profissionais para trabalhar com os conteúdos da área, é preciso prepará-los pedagogicamente e para as especificidades da Educação do Campo, bem como da realidade camponesa da região.

Essa complexidade vai além disso, segundo Faleiro e Farias (2016, p. 93), existem grandes desafios para as LEdoCs e o ensino das Ciências da Natureza, como por exemplo:

Há grande dificuldade em se ter professores formadores capacitados e familiarizados com ações específicas da Educação do Campo e com o trabalho interdisciplinar. Essa dificuldade é devida à própria estrutura e Currículos encontrados nos cursos de formação de professores, onde a padronização, disciplinarização, fragmentação e a homogeneização vigora na maioria das IES brasileiras. Outro desafio é articular interdisciplinarmente os conteúdos teóricos e as realidades sociais do Campo, que acontece pela falta de conhecimento e vivências sobre as especificidades do Campo.

Ademais, podemos acrescentar que a área em questão é considerada de difícil compreensão, a julgar por se tratar da junção de três disciplinas (supostamente difíceis), nas quais há grande déficit de formação e índice de evasão durante o Curso. Dessa forma, os Quadros 3 e 4 evidenciam como essas LEdoCs estão lidando com essas complexidades, ou seja, como elas estão organizando os componentes curriculares de modo a contemplar uma melhor formação docente. 


\section{4 - CONSIDERAÇÕES FINAIS}

Nossa intenção com essas análises não é propor uma maneira certa ou errada de se formar professores do Campo nem tecer comparações entre os PPPs dos cursos analisados, mas compreender como esses processos formativos, mesmo que parcialmente, contribuem para o fortalecimento da Educação do Campo. Realidade parcial, porque evidenciamos que, mesmo considerando a análise dos PPPs desses cursos, indispensáveis para compreensão do processo de construção, desenvolvimento e mudanças da LEdoC, nosso objeto de análise é limitado, não sendo possível inferirmos se as complexidades discutidas neste trabalho são observadas na prática ou se os princípios ausentes nos PPPs estão sendo praticados. Outra limitação do nosso estudo foi encontrar, nos sites institucionais, PPPs desatualizados, com exceção de P-4 (2017), o que nos leva inferir que pode acontecer de algum dado não corresponder à realidade do Curso.

Outro aspecto a considerar é como a LEdoC propõe a superação das tendências dominantes nas políticas de educação do meio rural para o desenvolvimento emancipatório no Brasil, é importante ter cautela com as aproximações dos princípios da Educação do Campo aos princípios escolanovistas e relativistas presentes em pedagogias não-críticas. Isso porque este tipo de proximidade pode implicar profundamente no desenvolvimento e organização individual e coletivo das lutas sociais. Além disso, é preciso compreendermos em que bases ideológicas pertencem esses princípios pedagógicos, porque, mesmo que colocadas como neutras, não existe neutralidade em práticas educativas e escolares, sempre há uma ideologia imersa. Nesse caso, o resultado pode ser interpretações e assimilações que comprometem os princípios da Educação do Campo, assemelhando-se mais ao discurso hegemônico.

Sobre isso, apenas P-1 assume o materialismo histórico-dialético como abordagem filosófica para o trabalho pedagógico escolar, sendo que P-4 e P-5 deixa isso subentendido. P-2 e P-3 não se posicionam quanto a esse aspecto. Vale destacar que os cincos documentos defendem uma perspectiva freireana da Educação, pautada em uma práxis libertadora e dialógica, na qual se reconhece que toda prática pedagógica é também política.

Com relação à questão curricular enfatizada nesse estudo, os cinco documentos analisados distribuem as disciplinas das Ciências da Natureza distintamente, sendo que a carga horária disposta entre as disciplinas de Biologia, Física e Química não é igual. A maioria dos cursos dão maior ênfase ao estudo de conteúdos relacionados à Biologia. Isso pode prejudicar a formação desse (a) futuro (a) docente, no sentido de que ele (ela) não tenha domínio científico de todas as disciplinas que correspondem sua área de habilitação. A apropriação do conhecimento científico é fundamental para a compreensão da totalidade e da complexidade dos processos encontrados na realidade e de assuntos relacionadas a essa área.

Nossa intenção não é inferiorizar as LEdoCs com habilitação em CN, mas expor que um melhor aprofundamento do conhecimento historicamente já conquistado pode garantir que esse (a) uma compreensão mais ampla de conceitos e suas aplicações durante a abordagem no Ensino Fundamental e Médio. Ressaltamos ainda que essa discussão sobre as CH não 
é para contradizer a formação por área, haja vista que as IES estão formando professores/ as por área e não por disciplinas. Contudo, este tipo de formação é complexo, além de habilitar profissionais para trabalhar interdisciplinarmente com os conteúdos da área, é preciso prepará-los pedagogicamente e para as especificidades da Educação do Campo, bem como da realidade camponesa da região. 


\section{5 - REFERÊNCIAS}

ALMEIDA, Juliano da Silva Martins de. Egressos em Educação do Campo com habilitação em Ciências da Natureza: enfrentamentos e diretrizes. 2019. 93 f. Relatório Preliminar de Pós-Doutorado - Programa de Pós-Graduação em Educação (PPGEDUC), Universidade Federal de Goiás - Regional Catalão, 2019.

BEZERRA NETO, Luiz. BEZERRA, Maria Cristina dos Santos. A importância do materialismo histórico na formação do educador do Campo. In: Revista HISTEDBR On-line, Campinas, número especial, ago. 2010, p. 251-272. Disponível em: https:// periodicos.sbu.unicamp.br/ojs/index.php/histedbr/article/view/8639762/15002, acesso em 09/01/2020.

BRANDÃO, Carlos Rodrigues. O que é educação popular. São Paulo: Brasiliense, 2012.

BRASIL. [Edital n. 02/2012]. Edital n. 02/2012 - SESU/SETEC/SECADI/MEC, de 31 de agosto de 2012 (Chamada Pública para seleção de Instituições Federais de Educação Superior - IFES e de Institutos Federais de Educação, Ciência e Tecnologia - IFET, para criação de cursos de Licenciatura em Educação do Campo, na modalidade presencial). Disponível em: http://portal.mec.gov.br/index.php?option $=$ com docman\&view $=$ download\&alias $=13300-\mathrm{e}-$ dital-02-2012-sesu-setec-secadi-31-agosto-2012-pdf\&category slug=junho-2013-pdf\&Ite$\underline{\mathrm{mid}=30192}$, acesso em 25/03/2019.

BRASIL. Programa Nacional de Educação de Educação do Campo - Pronacampo - Documento orientador, 2013. Disponível em: http://portal.mec.gov.br/index.php?option=com docman\&view $=$ download\&alias $=13214$-documento-orientador-do-pronacampo-pdf\&Itemid $=30192$, acesso em 07/01/2020.

FALEIRO, Wender. FARIAS, Magno Nunes. Formadores de professores em Educação do Campo em Goiás. In: Revista Brasileira em Educação do Campo, v. 1, n. 1, p. 88-106, jan. / jun. 2016.

FARIAS, Magno Nunes. FALEIRO, Wender. Princípios do movimento de Educação do Campo: análise dos Projetos Político-Pedagógicos das LEdoCs do Centro-Oeste brasileiro. Uberlândia, MG: Navegando Publicações, 2019.

FRANCO, Maria Laura P. B. Análise do Conteúdo, 5. ed. Campinas: Editora Autores Associados, 2018.

MOLINA, Mônica Castagna. SÁ, Laís Mourão. Licenciatura em Educação do Campo. In: CALDART, Roseli Salete. PEREIRA, Isabel Brasil. ALENTEJANO, Paulo. FRIGOTTO, Gaudêncio. (Orgs.) Dicionário da Educação do Campo, 2. ed. Rio de Janeiro, São Paulo: Escola Politécnica de Saúde Venâncio, Expressão Popular, 2012, p. 468-474. 
RIBEIRO, Geize Kelle Nunes. FALEIRO, Wender. ALMEIDA, Juliano da Silva Martins de. Organização político-pedagógico na formação de professores do Campo em Ciências da Natureza no Brasil. Goiânia, GO: Editora Kelps, 2020. Disponível em: https://www.kelps. com.br/wp-content/uploads/2020/10/A-organizacao-politico-pedagogica_ebook.pdf, acesso em 23/11/2020.

SOARES, Magda. Linguagem e escola: uma perspectiva social. 18. ed. São Paulo: Contexto, 2017. 